\title{
Cardiogenic Shock Caused by SARS-CoV-2 in a Patient with Serial Negative Nucleic Acid Amplification Tests. Case Report
}

\author{
Aina Gomila-Grange ${ }^{1}$ (D) $\cdot$ M. Espasa ${ }^{2} \cdot$ E. Moglia $^{3}$ \\ Accepted: 27 August 2020 / Published online: 31 August 2020 \\ (C) Springer Nature Switzerland AG 2020
}

\begin{abstract}
Myocarditis is an unusual manifestation of severe acute respiratory syndrome coronavirus 2 (SARS-CoV-2). It has been associated with increased severity of disease and mortality. The diagnosis of coronavirus disease 2019 (COVID-19) is based on positivity of nucleic acid amplification tests (NAAT) of respiratory samples. We report the case of a patient with cardiogenic shock caused by SARS-CoV-2 myocarditis with serial negative upper and lower respiratory nucleic acid amplification tests. Diagnosis was made by serology (positive $\operatorname{IgM}+\operatorname{IgA}$ and $\operatorname{IgG}$ ) from patient's serum sample of day 10 after symptoms' initiation.
\end{abstract}

Keywords Severe acute respiratory syndrome coronavirus 2 C Coronavirus disease $2019 \cdot$ Myocarditis $\cdot$ Serology

\section{Introduction}

Severe acute respiratory syndrome coronavirus 2 (SARSCoV-2) emerged in Wuhan, China, in December 2019 and rapidly spread to different countries being declared a pandemic. It has caused more than 21 million infections and more than 700,000 deaths worldwide since its origin [1,2]. Although respiratory symptoms are the most common manifestation of coronavirus disease 2019 (COVID-19), cardiovascular involvement has been described in up to $20 \%$ of hospitalized patients $[3,4]$. Cardiac injury due to SARS-CoV-2 refers to blood levels of troponin I concentration above the upper reference limit and seems to be caused by a combination of direct viral myocardial interstitial damage and organ injury caused by the severe acute systemic inflammatory response triggered by the infection [5-7]. Arrhythmias and acute coronary syndrome may also occur in the context of hypoxemia, myocardial inflammation and thrombotic phenomena $[8,9]$. In

This article is part of the Topical Collection on Covid-19

Aina Gomila-Grange

agomila@tauli.cat

1 Infectious Diseases Department, Consorci Corporació Sanitària Parc Taulí, Parc Taulí 1, Sabadell, 08208 Barcelona, CP, Spain

2 Microbiology Unit, Consorci Corporació Sanitària Parc Taulí, Sabadell, Barcelona, Spain

3 Intensive Care Unit, Consorci Corporació Sanitària Parc Taulí, Sabadell, Barcelona, Spain different published studies, patients with myocardial involvement by COVID-19 usually had cardiovascular underlying conditions and showed worse prognosis, including increased risk of intensive care unit admission and mortality compared with those without cardiac injury. Myocarditis has been recognized as one of the most common forms of cardiac injury [4, 10-12].

Here, we report the case of a healthy man presenting with cardiogenic shock caused by SARS-CoV-2 myocarditis, without pneumonia, in whom nucleic acid amplification tests (NAAT) were repeatedly negative in upper and lower respiratory tract samples. Diagnosis of acute disease was made by positivity of serology.

\section{Case Report}

A 39-year-old man original from Uruguay and living in Spain for the last 2 years was admitted to our emergency department because of fever, right flank pain and diarrhoea of 6 days. He was a former smoker and had a daily alcohol intake of $68 \mathrm{~g}$. He had been at home with his wife and his four kids during the previous month, when lockdown started in Spain. At admission, he had fever of $38.6{ }^{\circ} \mathrm{C}$, hypotension and tachycardia, and urgent blood test showed leucocytosis of $22.9 \times 10^{9} / \mathrm{L}$ (neutrophils $92 \%$, lymphocytes $3.1 \%$ ), elevation of D-dímer (2132 ng/mL, $N<580)$, ferritin (3188 ng/mL, $N<400)$, lactate dehydrogenase (552 $\mathrm{U} / \mathrm{L}, N<225$ ), transaminases (ALT $103 \mathrm{U} / \mathrm{I}[N<41]$, AST $88 \mathrm{U} / \mathrm{I}[N<38])$, prothrombin time 
(1.33, $[N<1.2])$ and c-reactive protein $(33.3 \mathrm{mg} / \mathrm{dL}[N<$ 0.5]). Two nasopharyngeal SARS-CoV-2 NAATs separated $24 \mathrm{~h}$ were negative. He had a normal chest X-ray and a thoraco-abdominal computed tomography (CT) discarded lung infiltrates but showed signs of ileocolitis. Serum therapy and intravenous (IV) antibiotic treatment with meropenem $1 \mathrm{~g} / 8 \mathrm{~h}$ plus metronidazole $500 \mathrm{mg} / 8 \mathrm{~h}$ were started after taking blood tests. Due to persistent hypotension and tissular hypoperfusion signs (high lactate, low venous oxygen saturation, renal and liver failure) despite fluid resuscitation, he was admitted to the intensive care unit.

Concomitantly, elevation of myocardial damage enzymes (troponin I raised to $3800 \mathrm{ng} / \mathrm{mL}[N<13 \mathrm{ng} / \mathrm{mL}]$ and creatine kinase to $440[N<195])$ and pro-brain natriuretic peptide (pro-BNP) to $27,696 \mathrm{pg} / \mathrm{mL}(N<125)$ were also observed. There was no ST segment alteration on electrocardiogram, and an echocardiogram showed severe biventricular dysfunction, with left ventricular ejection fraction (LVEF) of $30 \%$ due to diffuse hypokinesis, diastolic dysfunction and slight posterior pericardial effusion without tamponade signs. Increased cardiac filling pressures were registered.

With these data, a presumptive diagnosis of cardiogenic shock due to myocarditis was made, and although he had two negative nasopharyngeal SARS-CoV-2 NAATs, considering the current epidemiological context, treatment with hydroxychloroquine, azithromycin and $600 \mathrm{mg}$ of IV tocilizumab was started, as stated per protocol at the moment. He also received depletive treatment and intubation because of dyspnoea. Dobutamine and nitroprusside perfusions were started due to worsening of ventricular systolic function to $20 \%$.

Detection of SARS-CoV-2 NAAT on bronchoalveolar lavage was negative by amplification of RdRp, E and $\mathrm{N}$ genes (GeneFinderTM COVID-19 Plus RealAmp Kit, Osang Healthcare Korea). Other respiratory viral infections (influenza, parainfluenza, common coronavirus, Middle East respiratory syndrome virus, adenovirus, metapneumovirus, sincitial respiratory virus, rhinovirus/enterovirus) and Chlamydia pneumoniae, Mycoplasma pneumoniae and Bordetella were discarded by a multiplex NAAT of the bronchoalveolar lavage (Filmarray ${ }^{\circledR}$ Respiratory Panel 2 Plus, BIOFIREbioMerieux). Moreover, other myocarditis and ileocolitis infective aetiologies were discarded by serology: humanimmunodeficiency virus, $\mathrm{C}$ and $\mathrm{B}$ hepatitis viruses, cytomegalovirus, Epstein-Barr virus, human-herpes-virus 6, A and B coxackie virus, echovirus, adenovirus, Yersinia enterocolitica and Trypanosoma cruzi. Diarrhoea promptly disappeared, and faeces sample could not be analysed. All blood tests performed were negative.

Hemodynamic instability started improving after $72 \mathrm{~h}$ and troponin I concentration descended, allowing withdrawal of aminas, nitroprusside and intubation. A coronary angiography discarded coronary artery injury, and a new echocardiogram after 10 days showed complete normalization of ventricular function. A SARS-CoV-2 serology performed by enzymelinked immunosorbent assay (COVID-19 IgG and IgM + IgA, Vircell@) on patient serum's sample of day 10 after symptom's initiation showed positive results for both $\operatorname{IgM}+$ IgA and IgG, confirming the diagnosis of COVID-19. One month after discharge, he was completely recovered.

\section{Discussion}

Here, we report an infrequent and severe manifestation of COVID-19 that could be diagnosed by serology after multiple negative respiratory tract NAAT.

Diagnosis of myocarditis with cardiogenic shock was made on the basis of elevation of troponin I concentration, typical echocardiography signs including biventricular diffuse dysfunction and pericardial effusion in the background and systemic hypoperfusion without fluid depletion [6]. Although this complication has been described [3, 5, 7, 8, 13-15], its frequency seems to be low and the real incidence has not been determined. Although it has been associated with poor prognosis, the fact that our patient was young and did not have a cardiovascular predisposing condition could explain the good evolution he had.

The microbiological confirmation of COVID-19 diagnosis was made by positivity of SARS-CoV-2 serology after excluding other microbiological causes of myocarditis and ileocolitis. It is remarkable that, contrary to our case, all previous reported patients with cardiac involvement had a positive respiratory NAAT and most of them had pneumonia $[3,5$, 7-9, 13-15]. Nevertheless, there is also evidence that many patients with compatible clinical picture of COVID-19 have negative nasopharyngeal NAAT [16]. A previous study performed on inpatients with COVID-19 confirmed by NAAT in 3 Chinese hospitals showed that nasal NAAT had a positivity rate of $63 \%$, pharyngeal of $32 \%$ and bronchoalveolar lavage of $93 \%$ [17]. One study evaluating SARS-CoV-2 serology showed that seroconversion of symptomatic patients occurred in $50 \%$ of cases at 7 days of symptoms and in $100 \%$ at 14 days [18]. As some authors state, serology may play a role in the diagnosis of acute COVID-19, specially in those patients with suggestive symptoms and repeated negative NAAT [19].

In conclusion, this case shows an unusual severe manifestation of COVID-19 without respiratory involvement. It highlights the utility of serology as an alternative diagnostic tool when clinical suspicion of COVID-19 is high but serial respiratory NAAT are negative.

Authors' Contributions All authors contributed to the acquisition of the data, drafting of the manuscript, critical revision of the manuscript for important intellectual content and final approval of the version to be submitted. 


\section{Compliance with Ethical Standards}

Conflict of Interest The authors declare that they have no conflict of interest.

Informed Consent Informed consent for publication was obtained from the patient.

\section{References}

1. Guan W, Ni Z, Hu Y, Liang W, Ou C, He J, et al. Clinical characteristics of coronavirus disease 2019 in China. N Engl J Med. 2020;382:1708-20. https://doi.org/10.1056/NEJMoa2002032.

2. WHO Coronavirus Disease (COVID-19) situation reports. 209-16 August 2020. https://www.who.int/emergencies/diseases/novelcoronavirus-2019/situation-reports. Accessed 20 August 2020.

3. Zeng JH, Liu YX, Yuan J, Wang FX, Wu WB, Li JX, et al. First case of COVID-19 complicated with fulminant myocarditis: a case report and insights. Infection. 2020:1-5. https://doi.org/10.1007/ s15010-020-01424-5.

4. Boukhris M, Hillani A, Moroni F, Annabi MS, Addad F, Harada Ribeiro M, et al. Cardiovascular implications of the COVID-19 pandemic: a global perspective. Can J Cardiol. 2020. https://doi. org/10.1016/j.cjca.2020.05.018.

5. Tavazzi G, Pellegrini C, Maurelli M, Belliato M, Sciutti F, Bottazzi A, et al. Myocardial localization of coronavirus in COVID-19 cardiogenic shock. Eur J Heart Fail. 2020;22:1-5. https://oi.org/10. 1002/ejhf.1828.

6. Ranard LS, Fried JA, Abdalla M, Anstey DE, Givens RC, Kumaraiah D, et al. Approach to acute cardiovascular complications in COVID-19. Infect Circ Heart Fail. 2020;13(7):e007220. https://doi.org/10.1161/CIRCHEARTFAILURE.120.007220.

7. Anupama BK, Thapa SS, Amzuta I. Transient cardiomyopathy in a patient with coronavirus disease-2019. J Investig Med High Impact Case Rep. 2020;8:2324709620947577. https://doi.org/10.1177/ 2324709620947577.

8. Sánchez-Recalde Á, Solano-López J, Miguelena-Hycka J, MartínPinacho JJ, Sanmartín M, Zamorano JL. COVID-19 and cardiogenic shock. Different cardiovascular presentations with high mortality. Rev Esp Cardiol (Engl Ed). 2020;73(8):669-72. https://doi.org/ 10.1016/j.rec.2020.04.012.

9. Kim HN, Lee JH, Park HS, Yang DH, Jang SY, Bae MH, et al. A case of COVID-19 with acute myocardial infarction and cardiogenic shock. J Korean Med Sci. 2020;35(27):e258. https:// doi.org/10.3346/jkms.2020.35.e258.

10. Siripanthong B, Nazarian S, Muser D, Deo R, Santangeli P, Khanji MY, et al. Recognizing COVID-19-related myocarditis: the possible pathophysiology and proposed guideline for diagnosis and management. Heart Rhythm. 2020:S1547-5271(20)30422-7. https:// doi.org/10.1016/j.hrthm.2020.05.001.

11. Akhmerov A, Marbán E. COVID-19 and the heart. Circ Res. 2020;126:1443-55. https://doi.org/10.1161/CIRCRESAHA.120. 317055.

12. Bansal M. Cardiovascular disease and COVID-19. Diabetes Metab Syndr Clin Res Rev. 2020;14:247-50. https://doi.org/10.1016/j. dsx.2020.03.013.

13. Bemtgen X, Krüger K, Supady A, Dürschmied D, Schibilsky D, Bamberg F, et al. First successful treatment of COVID-19 induced refractory cardiogenic plus vasoplegic shock by combination of pVAD and ECMO - a case report. ASAIO J. 2020;66(6):607-9. https://doi.org/10.1097/MAT.0000000000001178.

14. Inciardi RM, Lupi L, Zaccone G, Italia L, Raffo M, Tomasoni D, et al. Cardiac involvement in a patient with coronavirus disease 2019 (COVID-19). JAMA Cardiol. 2020;2019:1-6. https://doi. org/10.1001/jamacardio.2020.1096.

15. Doyen D, Moceri P, Ducreux D, Dellamonica J. Myocarditis in a patient with COVID-19: a cause of raised troponin and ECG changes. Lancet. 2020;395(10235):1516. https://doi.org/10.1016/S01406736(20)30912-0.

16. Winichakoon $P$, Chaiwarith R, Liwsrisakun C, Salee P, Goonna A, Limsukon QKA. Negative nasopharyngeal and oropharyngeal swabs do not rule out COVID-19. J Clin Microbiol. 2020;58:1-2. https://doi.org/10.1128/JCM.00297-20.

17. Wang W, Xu Y, Gao R, Lu R, Han K, Wu G, et al. Detection of SARS-CoV-2 in different types of clinical specimens. JAMA. 2020;323(18):1843-4. https://doi.org/10.1001/jama.2020.3786.

18. Wölfel R, Corman VM, Guggemos W, Seilmaier M, Zange S, Müller MA, et al. Virological assessment of hospitalized patients with COVID-2019. Nature. 2020;581(7809):465-9. https://doi.org/ 10.1038/s41586-020-2196-x.

19. Tang Y, Schmitz JE, Persing DH, Stratton CW. Laboratory diagnosis of COVID-19: current issues and challenges. J Clin Microbiol. 2020;58:1-9. https://doi.org/10.1128/JCM.00512-20.

Publisher's Note Springer Nature remains neutral with regard to jurisdictional claims in published maps and institutional affiliations. 